\title{
THE INFLUENCE OF SAMPLING TIME TO SERUM GLIAL FIBRILLARY ACIDIC PROTEIN (GFAP) LEVELS IN ACUTE STROKE
}

\author{
Neila Raisa ${ }^{1}$, Hidayat Sujuti ${ }^{2}$, Hari Purnomo ${ }^{1}$, Masruroh Rahayu ${ }^{1}$, Mochamad Dalhar $^{1}$ \\ Correspondence: neilaraisa@gmail.com \\ ${ }^{1}$ Department of Neurology Faculty of Medicine Brawijaya University, Malang, Indonesia. \\ ${ }^{2}$ Department of Biochemistry/Biomolecular Faculty of Medicine Brawijaya University, Malang, Indonesia.
}

\author{
Article History: \\ Received: May 17, 2018 \\ Accepted: June 5, 2018 \\ Published: January 1, 2019 \\ Cite this as: \\ RaisaN, Sujuti H, Purnomo H, \\ Rahayu M, Dalhar M. The \\ influence of sampling time to \\ serum glial fibrillary acidic \\ protein (gfap) levels in acute \\ stroke. Malang Neurology \\ Journal; 2019.5:30-33. DOI: \\ http://dx.doi.org/10.21776/ub.mnj \\ 2019.005.01.5
}

\section{ABSTRACT}

Background: Serum Glial Fibrillary Acidic Protein (GFAP) is a great potential for biomarker that is widely studied as a diagnostic biomarker of acute stroke. Sampling within 6 hours after onset is the best time window, but in Indonesia, stroke patients often arrive late more than 6 hours.

Objective: To identify the difference in time of blood sampling with serum GFAP levels within 24 hours onset of ischemic stroke (IS) patients and intracerebral hemorrhage (ICH) strokes.

Methods: Cross-sectional analysis with purposive sampling, sampling in IS and ICH strokes that arrive at the ER within 24-hour on-site. The serum GFAP examination was performed with ELISA.

Results: In this study, 41 acute stroke patients with 24-hour onset of each stroke were grouped into group 1 ( $<6$ hours), group 2 (6-12 hours) and group 3 (12-24 hours). One Way ANOVA and Tukey's analysis showed no significant difference in GFAP levels among the three groups in both IS and ICH. Conclusion: There was no significant difference in GFAP levels in samples $<6$ hours, $6-12$ hours, and 12-24 hours in ischemic strokes and ICH strokes.

Keywords: GFAP, time of blood sampling, acute stroke

\section{Introduction}

Stroke is the third etiology of morbidity and mortality in Western population after ischemic heart disease and cancer. ${ }^{1}$ Based on WHO, in 2001, $86 \%$ of stroke-related mortality worldwide was occurred in underdeveloped country, whereas Southeast Asia predicted as main contributor for stroke-related mortality. ${ }^{2}$ This prevalence might be as high as death caused by coronary heart disease, and stroke and coronary heart disease could be occurred 10 years earlier compared with other region. ${ }^{2}$

By only using history taking and physical examination, diagnosis of stroke could be established $92 \%$ by general physicians. However, this approach is still difficult to differentiate ischemic and intracerebral hemorrhage stroke. Because of limited time (only several hours), the decision to perform thrombolytic therapy should be determined as soon as possible. Imaging is the only one of the modalities which could differentiate ischemic and hemorrhage. ${ }^{1}$ Moreover, acute phase of hypertension management (> 180 $\mathrm{mmHg}$ ) is an essential aspect in the treatment of hemorrhagic stroke and this part has a different approach with ischemic stroke (> $220 \mathrm{mmHg}$ ). Recently, in order to save penumbra tissue, thrombolytic therapy is possible to be performed in the ischemic stroke before 4.5 hours of onset. $^{3,4,5}$ Interestingly, current research demonstrated was concerned about the efficacy of thrombectomy procedure for ischemic stroke with onset 8-16 hours although the outcome was varied. ${ }^{6,7}$
In particular country with limitation of CT and MRI is the obstacles for establishing the type of stroke. Recently, research focused on determination of biomarkers in stroke diagnosis had been performed. Ideally, these biomarkers should have both high sensitivity and specificity and feasible to be conducted in pre-hospital setting without imaging studies.

Glial fibrillary acidic protein (GFAP) is a specific intermediary filament protein located in the brain tissue that responsible for maintaining the structure and migration of astroglia. ${ }^{8}$ Physiologically, GFAP is not secreted actively and can't detected in the serum of healthy individuals. An astrogliosis condition in stroke could increase the GFAP expression which could be detected in peripheral serum. Typically, tissue damage in hemorrhagic stroke is occurring faster as compared to ischemic stroke. This phenomenon influences the GFAP release in the early phase of both types of stroke, thereby considered to have diagnostic value, especially in 4-6 hours from onset. ${ }^{9,10}$

Delayed treatment caused by transport problem is a common issue in underdeveloped countries, even in China only $24.8 \%$ stroke patients arrived at ER during 2 hours of onset (average 4 hours; $1.5-14$ hours). ${ }^{11}$ Similar to this situation, in Indonesia, mostly stroke patient arrived at ER after 6 hours on onset (average 18 hours). Delayed admission to hospital is caused by patient's knowledge about stroke symptoms, access limitation and transportation problem, and also patient's family decision. ${ }^{12}$ 
Based on different patient's characteristics in Indonesia, this research was aimed to investigate the comparison of GFAP level in the early 24 hours of stroke onset.

\section{Methods}

This study was designed as cross sectional with purposive sampling approach. Patient with ischemic and intracerebral hemorrhage stroke who admitted to Department of Neurology, Saiful Anwar General Hospital, Malang, Indonesia before 24 hours of onset were included in this study. This study was conducted for 3 months (November 2016 - January 2017). All procedures in this study were approved by Ethical Committee, Faculty of Medicine, Universitas Brawijaya. The inclusion criteria were as follows: age $>40$ years old, stroke onset $<24$ hours, the diagnosis was established by CT, and informed consent. Exclusion criteria were as follows: patient with a previous history of stroke, malignancy, head trauma, and cerebral infection. The blood sample was taken shortly after patient's admission. GFAP levels were measured by ELISA method (Bioassay Technology Laboratory, China). Determination of stroke type was conducted by CT as the gold standard and performed during 24 hours of onset. Each stroke type was grouped by the onset of stroke as follows: Group 1 ( $<6$ hours), Group 2 (6-12 hours) and Group 3 (1224 hours). Statistical analysis was done using ANOVA and post hoc analysis (Tukey) to compare the GFAP level between groups in each stroke type.

\section{Results}

This study included 41 patients (20 subjects with ischemic stroke, 21 subjects with hemorrhagic stroke) as research subject who had fulfilled inclusion criteria. Of 20 subjects with ischemic stroke, $10(50 \%)$ subjects were male and 10 $(50 \%)$ subjects were female with mean of age $62,9 \pm 9,82$ years old. In hemorrhagic stroke groups, 13 subjects $(61.9 \%)$ were male and the remaining (38.10\%) were female with mean of age $64.33 \pm 10.7$ years old. Baseline characteristics of subjects and distribution of onset could be seen in Table 1 and Figure 1, respectively. The almost straight distribution of serum GFAP level in Figure 2 showed that the sampling time did not affect GFAP levels.

Table 1. Baseline Characteristics.

\begin{tabular}{lll}
\hline Parameter & $\begin{array}{l}\text { Ischemic } \\
\text { Stroke }\end{array}$ & $\begin{array}{l}\text { Intracerebral } \\
\text { Hemorrhage } \\
\text { Stroke }\end{array}$ \\
\hline $\begin{array}{l}\text { Age (Mean } \pm \text { SD) } \\
\text { (years) }\end{array}$ & $62.9 \pm 9.82$ & $64.33 \pm 10.70$ \\
Sex & & \\
Male $(\%)$ & 50 & 61.90 \\
Female $(\%)$ & 50 & 38.10 \\
Time of blood & $6.78 \pm 5.36$ & $6.45 \pm 4.60$ \\
sampling from onset & & \\
(Mean \pm SD) (hours) & &
\end{tabular}

Statistical analysis in Table 2 showed that GFAP level was not significantly different between groups in Ischemic stroke (One way ANOVA, p = 0.710) and intracerebral hemorrhagic stroke (One way ANOVA, $\mathrm{p}=0.268$ ).

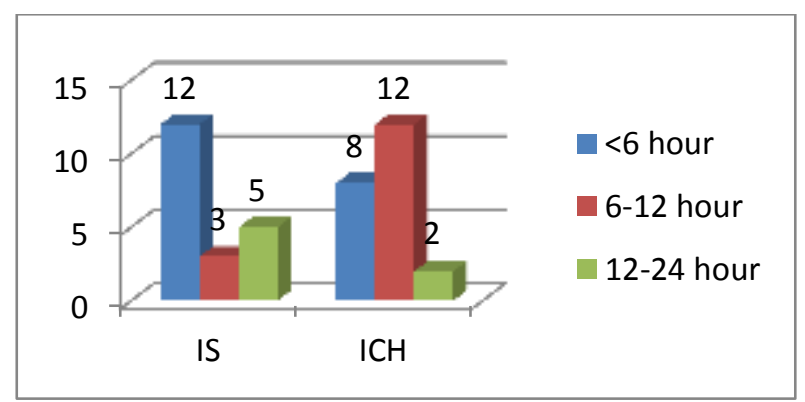

Figure 1. Patient's distribution based on time of blood sampling from the onset of stroke.

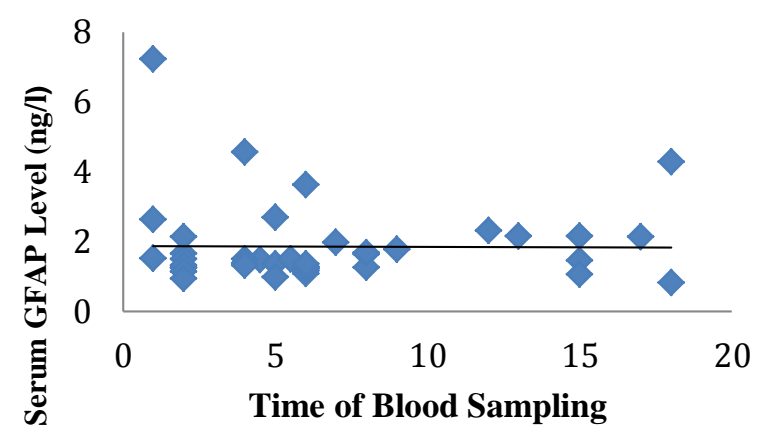

Figure 2. Distribution of serum GFAP level based on time of blood sampling.

Table 2. Statistical Analysis.

\begin{tabular}{cccccc}
\hline Variable & Group & $\mathrm{n}$ & Mean & $\begin{array}{c}\text { Std. } \\
\text { Deviation }\end{array}$ & Sig \\
\hline GFAP in & $<6$ & 12 & 2.33 & 1.79 & 0.710 \\
IS & $6-12$ & 3 & 1.78 & 0.16 & \\
& $>12$ & 5 & 1.77 & 0.49 & \\
& Total & 20 & 2.11 & 1.41 & \\
\hline GFAP in & $<6$ & 8 & 33.55 & 9.54 & 0.268 \\
ICH & $6-12$ & 11 & 38.18 & 17.11 & \\
& $>12$ & 2 & 51.31 & 48.46 & \\
& Total & 21 & 37.66 & 17.92 & \\
\hline
\end{tabular}

\section{Discussion}

Astrocyte (astroglia) is marked by a unique protein structure termed Glial Fibrillary Acidic Protein (GFAP). GFAP was abundantly expressed in central nervous system exclusively in astrocyte and few in peripheral nervous systems (e.g. non-myelinated Schwann cell of the sciatic nerve). GFAP also found slightly in glial cell of enteric nervous system and its fiber in submucosal and muscular layer. $^{13,14}$

Lesion in brain tissue could induce release of GFAP-BDP and astrocyte-derived GFAP into interstitial or extracellular fluid, which in turn would create an equilibrium with cerebrospinal fluid compartment in the subarachnoid space before further excreted in systemic circulation through direct venous drainage (lymphatic pathway), or alternatively through cerebrospinal flow then diffused via damaged blood brain barrier. ${ }^{13}$

In acute intracerebral hemorrhagic stroke, shear stress and mass effect caused by hematoma expansion induce sudden onset mechanical destruction to brain tissue and directly trigger necrosis to neuronal cells, glial cells, and also blood brain barrier damage. Most cellular debris, including specific protein such as GFAP and S100B were excreted to extracellular compartment and systemic circulation. Neuronal cells located on perimeter of hematoma could 
survive when bleeding occurred. However, accumulation of coagulation factor thrombin in clotting area together with hemoglobin and $\mathrm{Fe}$ could induce pathophysiological cascade and later cause edema formation and secondary damage. Peri-hematomal cells will suffer from necrosis and apoptosis, which will be at peak at 24 and 72 hours after bleeding onset. $^{15}$

On the contrary, in ischemic stroke, damage and necrosis of neuron and also astrocyte considered to be occurring slowly. Histopathologically, cell death phase of necrosis stage, which characterized by lysis and release of cellular debris into the extracellular compartment might not detected in the first 12 hours after the arterial occlusion. The pattern of GFAP serum concentration demonstrated the same pattern with healthy individuals. Sequentially, at the second day after the onset (24-48 hours), GFAP levels will be elevated. This hypothesis underlying the basic theory about the difference pattern of GFAP release in both types of stroke. ${ }^{15}$

Regarding the time of blood sampling of ischemic stroke $(6,78 \pm 5,36$ hours) and intracerebral hemorrhagic stroke $(6,45 \pm 4,60$ hours), there were no statistical differences of GFAP levels between three groups in ischemic stroke (ANOVA, $\mathrm{p}=0.710$ ) and intracerebral hemorrhagic stroke (ANOVA, $\mathrm{p}=0.268$ ).

In ischemic stroke, GFAP levels detected in serum are very low in the first 6 hours, 6-12 hours, and also 12-24 hours after the onset of occlusion, thereby there were no significant GFAP level differences between all groups. Previous studies had been demonstrated that the serum GFAP concentration in ischemic stroke was risen in the second day after onset (24-48 hours after onset). ${ }^{16,17}$ Conversely, in the case of intracerebral hemorrhagic stroke, serum GFAP levels elevate steeply in the serum reflecting the sudden onset of damaged astrocytes. Consequently, in this situation, GFAP levels could be detected in the serum in the first 2 hours after the onset, continuously elevate until reach its peak at 6 or 12 hours after onset, and decrease slowly after 24 hours. This phenomenon affects the GFAP itself to be used as diagnostic tools, especially in the first 12 hours after stroke onset in which the serum concentration is still very low. ${ }^{16}$ On the other hand, in the group $1 \quad(<6$ hours), group 2 (6-12 hours) and also group 3 (12-24 hours), the serum concentration of GFAP is high in all groups and might be starting to decrease after 24 hours of stroke onset, thereby there were no significant differences between groups.

The limitation of this study is the absence of stratification based on location and advancement of the brain lesion in ischemic and hemorrhagic stroke. The advanced lesion or specific location might affect the serum GFAP levels. Moreover, the chosen sampling method (purposive sampling) might not represent the general population, thereby the result of this study could not be generalized in population. However, hopefully our data could be used as a basic evidence for further study focusing on this topic with a larger sample.

\section{Conclusion}

We conclude that there were no significant differences in serum GFAP level between groups (onset $<6$ hours, 6-12 hours, and 12-24 hours) in ischemic stroke and hemorrhagic stroke.

\section{Acknowledgement}

The author thanks to Brawijaya University and Saiful Anwar General Hospital, Malang, East Java, Indonesia for facilitating this research.

\section{References}

1. Saenger AK, Christenson RH. Stroke biomarkers: progress and challenges for diagnosis, prognosis, differentiation, and treatment. Clin Chem; 2010.56(1):21-33

2. Wasay M, Khatri IA, Kaul S. Stroke in south asian countries. nat rev neurol; 2014.10(3):135-43. DOI: http://dx.doi.org/10.1038/nrneurol.2014.13

3. Raychev R, Saver JL. Mechanical thrombectomy devices for treatment of stroke. Neurol Clin Pract; 2012.2(3):231-5.

DOI: 10.1212/CPJ.0b013e31826af206

4. Demaerschalk BM, Cheng NT, Kim AS. Intravenous thrombolysis for acute ischemic stroke within 3 hours versus between 3 and 4.5 hours of symptom onset. The Neurohospitalist; 2015.5(3):101-9. DOI: $10.1177 / 1941874415583116$

5. Wechsler LR. The 4.5-hour time window for intravenous thrombolysis with intravenous tissue- type plasminogen activator is not firmly established. Stroke; 2014.45(3):914-5. DOI: 10.1161/STROKEAHA.113.002701

6. Albers GW, Marks MP, Kemp S, Christensen S, Tsai JP, Ortega-Gutierrez S, et al. Thrombectomy for stroke at 6 to 16 hours with selection by perfusion imaging. N Engl J Med; 2018.378(8):708-18. DOI: 10.1056/NEJMoa1713973

7. Jovin TG, Chamorro A, Cobo E, de Miquel MA, Molina CA, Rovira A, et al. Thrombectomy within 8 hours after symptom onset in ischemic stroke. N Engl J Med; 2015.372(24):2296-306. DOI: 10.1056/NEJMoa1503780

8. Pekny M, Hol EM. Glial fibrillary acidic protein (gfap) and the astrocyte intermediate filament system in diseases of the central nervous system. Current Opinion in Cell Biology; 2015.32:121-30. DOI: 10.1016/j.ceb.2015.02.004

9. Foerch C, Curdt I, Yan B, Dvorak F, Hermans M, Berkefeld J, et al. Serum glial fibrillary acidic protein as a biomarker for intracerebral haemorrhage in patients with acute stroke. J Neurol Neurosurg Psychiatry; 2006.77(2):181-4

10. Dvorak F, Haberer I, Sitzer M, Foerch C. Characterisation of the diagnostic window of serum glial fibrillary acidic protein for the differentiation of intracerebral haemorrhage and ischaemic stroke. Cerebrovasc Dis; 2009.27(1):37-41. DOI: 10.1159/000172632

11. Jiang B, Ru X, Sun H, Liu H, Sun D, Liu Y, et al. Prehospital delay and its associated factors in first-ever stroke registered in communities from three cities in china. Sci Rep; 2016.6(February):1-11. DOI: 10.1038/srep29795 
12. Chadha V, Goel NK, Bhardwaj AK, Sharma A. Factors and decisions associated with delayed admission among stroke patients in a tertiary-care level hospital. Indian Journal of Research; 2018.7(7): 113-5. Available from: https://wwjournals.com/index.php/pijr/article/view/61 38/6079

13. Yang Z, Wang KKW. Glial fibrillary acidic protein: from intermediate filament assembly and gliosis to neurobiomarker. Trends Neurosci; 2015.38(6):364 74. DOI: http://dx.doi.org/10.1016/j.tins.2015.04.003

14. Tykhomyrov AA, Pavlova AS, Nedzvetsky VS. Glial fibrillary acidic protein (gfap): on the 45th anniversary of its discovery. Neurophysiology; 2016.48(1):54-71. DOI 10.1007/s11062-016-9568-8
15. Brunkhorst R, Pfeilschifter W, Foerch C. Astroglial proteins as diagnostic markers of acute intracerebral hemorrhage - pathophysiological background and clinical findings. Transl Stroke Res; 2010.246-51. DOI: 10.1007/s12975-010-0040-6

16. Dvorak F, Haberer I, Sitzer M, Foerch C. Characterisation of the diagnostic window of serum glial fibrillary acidic protein for the differentiation of intracerebral haemorrhage and ischaemic stroke. Cerebrovasc Dis; 2009.37-41. DOI: $10.1159 / 000172632$

17. Wunderlich MT, Wallesch CW, Goertler M. Release of glial fibrillary acidic protein is related to the neurovascular status in acute ischemic stroke. Eur $\mathrm{J}$ Neurol; 2006;1118-23. DOI: 10.1111/j.14681331.2006.01435.x 